\title{
A formação do cirurgião cardiovascular
}

\section{Luiz Carlos Bento de Souza*}

*Diretor da Divisão de Cirurgia

Instituto Dante Pazzanese de Cardiologia
A formação de um cirurgião cardiovascular representa um processo longo, progressivo e complexo, conferindo à instituição que o proporciona, grande responsabilidade.

$\mathrm{Na}$ maioria das vezes se completa após o período da residência, durante o decorrer da vida profissional.

O desenvolvimento de um programa de treinamento nessa especialidade deve enfocar três pontos fundamentais: formação humanística, cultura médica e habilidade manual.

O aprendizado de que o comportamento humano do médico deve exteriorizar o respeito pelo paciente faz com que o mesmo se torne o centro da mais cuidadosa atenção, e permite, ainda que no mais variado cenário existente o sofrimento, a incerteza e a preocupação sejam olhados com compaixão.

Independente da gravidade dos casos dos mais simples aos mais graves e complexos deva-se apresentar a serenidade necessária para tranquilizar e descontrair o paciente e seus familiares.

As informações necessárias para obtenção do "consentimento informado" devem ser claras e objetivas a fim de se obter um bom clima de entendimento evitando a causa mais frequente de queixas contra o atendimento médico.

Procurar tratar os colegas de profissão e demais profissionais com postura ética buscando sempre entender antes de julgar.

Interpretar a sala de operações como local de recato onde se deve dar tudo o que de melhor possuímos, estando sempre atentos para aprender o que ainda não sabe, evitando compreende-lo como palco do desfile de vaidades dos cirurgiões arrogantes, exercitando a humildade, qualidade das mais apreciadas no ser humano.

Manter o bom humor fazendo com que o astral do paciente eleve a confiança no procedimento.

Sentir a satisfação intima do resultado favorável, mas não reter a lágrima compartilhada com os familiares no insucesso.

A busca do conhecimento estrutura a cultura médica fazendo com que o conhecimento da Anatomia, Fisiopatologia, da clinica e das técnicas cirúrgicas, permitam a decisão pela conduta mais correta.

Que o cirurgião não seja um autônomo, robô, ou fazedor de operações, mas que tenha discernimento para conduzir os casos com maior acerto.

Entender que o resultado do ato operatório não se resume na alta hospitalar, mas sim na qualidade de vida que o tratamento cirúrgico proporcionara no futuro, mormente quando o paciente for uma criança onde o sucesso somente será avaliado décadas depois.

Estimular no jovem cirurgião a curiosidade científica, capaz de fazer germinar a inventividade que faz participar da evolução da ciência.

Buscar nas lições de seus velhos cirurgiões professores a seriedade, o rigor e a sabedoria no manuseio das soluções que algumas vezes não se encontram nas páginas dos compêndios, mas que se aprende no convívio diário com aqueles que consideramos ser nossos pontos de reparo.

Não permitir que o tempo ocioso, parasita, infrutífero, ocupe o espaço que possa ser dedicado ao aprimoramento. Esta é a fase da vida em que a energia da juventude deve capitalizar as melhores oportunidades futuras.

O desenvolvimento da habilidade manual deverá ser dirigida a permitir a execução das técnicas utilizadas nos procedimentos.

Aqui é onde se estabelece a importância e o valor da cirurgia experimental.

Neste laboratório terá inicio a preparação técnica do futuro cirurgião.

Este treinamento poderá ser desenvolvido em três etapas.

A primeira, inicial, compreende a realização de suturas em materiais tais como: borracha, couro, plástico.

Somente após a elaboração de suturas bem feitas e em tempo adequado é que poderemos passar a etapa seguinte.

Nesta segunda fase utilizam-se peças anatômicas (coração bovino ou porcino) que serão fixadas em caixas especialmente feitas, assemelhando-as ao coração dentro do tórax. Nestes experimentos podem ser realizadas suturas vasculares, na rede arterial coronária, troca valvar (mitral e aórtica) abertura e fechamento de defeitos septais, e procedimentos mais complexos como por exemplo, a reconstrução da raiz da aorta.

Após este aprimoramento passamos à terceira fase com a experimentação em animais vivos, aprendendo o regulamento estabelecido pela CONCEA - (Comissão Nacional da Cirurgia Experimental em Animais). Nesse modelo poderão ser realizadas técnicas com e sem circulação extracorpórea, provocando sensação mais próxima da real, em seres humanos.

Paralelamente será desenvolvido treinamento em simuladores representados por bonecos especialmente fabricados para esta finalidade onde poderão ser realizadas: entubação traqueal, passagem de cateter venoso central, drenagem pleural, traqueostomia e outros procedimentos. 
Esta sequência de treinamentos devera desenvolver-se em meses dentro do primeiro ano de residência.

Em laboratório de simulação mais completos poderá ser treinada cirurgia endovascular e procedimentos por toracoscopia. Esta fase será aplicada aos residentes de $2^{\circ}$ e $3^{\circ}$ anos.

Este período inicial de formação de um cirurgião cardiovascular deverá credenciar o candidato a participar de cirurgia em seres humanos com ocupação a ser definida dentro da equipe cirúrgica de rotina.
A participação da cirurgia experimental na preparação de jovens cirurgiões acelera seu aprimoramento obedecendo ao conceito de: "Aprender para operar e não operar para aprender".

$\mathrm{O}$ respeito pelo ser humano que está presente por baixo dos campos operatórios não deve ser reduzido a um objeto de treinamento. Somente deverá tocá-lo mãos treinadas e preparadas, considerando o paciente como o recipiente de nosso mais elevado respeito e dedicação.

\section{Reflexão do jovem cirurgião}

De posse do conhecimento e treinamento adquiridos,

Peço a Deus proteção e lucidez no desempenho das boas ações,

Mas deixe-me sentir o peso de sua mão,

No uso injusto e desumano de minha qualificação. 